\title{
Investigation of Archived Formalin-Fixed Paraffin-Embedded Pancreatic Tissue with Whole-Genome Gene Expression Microarray
}

\author{
Nete V. Michelsen, ${ }^{1}$ Klaus Brusgaard, ${ }^{1}$ Qihua Tan, ${ }^{1}$ Mads Thomassen, ${ }^{1}$ \\ Khalid Hussain, ${ }^{2}$ and Henrik T. Christesen ${ }^{3}$ \\ ${ }^{1}$ Department of Clinical Genetics, Odense University Hospital, Sdr Boulevard 29, 5000 Odense C, Denmark \\ ${ }^{2}$ Great Ormond Street Children's Hospital NHS Trust and Institute of Child Health, London WC1N 1EH, UK \\ ${ }^{3}$ H.C. Andersen Children's Hospital, Odense University Hospital, Sdr Boulevard 29, 5000 Odense C, Denmark
}

Correspondence should be addressed to Nete V. Michelsen, nete.michelsen@ouh.regionsyddanmark.dk

Received 9 August 2011; Accepted 26 September 2011

Academic Editors: A. B. Galosi and T. Yazawa

Copyright (C) 2011 Nete V. Michelsen et al. This is an open access article distributed under the Creative Commons Attribution License, which permits unrestricted use, distribution, and reproduction in any medium, provided the original work is properly cited.

\begin{abstract}
The use of formalin-fixed, paraffin-embedded (FFPE) tissue overcomes the most prominent issues related to research on relatively rare diseases: limited sample size, availability of control tissue, and time frame. The use of FFPE pancreatic tissue in GEM may be especially challenging due to its very high amounts of ribonucleases compared to other tissues/organs. In choosing pancreatic tissue, we therefore indirectly address the applicability of other FFPE tissues to gene expression microarray (GEM). GEM was performed on archived, routinely fixed, FFPE pancreatic tissue from patients with congenital hyperinsulinism (CHI), insulinoma, and deceased age-appropriate neonates, using whole-genome arrays. Although ribonuclease-rich, we obtained biologically relevant and disease-specific, significant genes; cancer-related genes; genes involved in (a) the regulation of insulin secretion and synthesis, (b) amino acid metabolism, and (c) calcium ion homeostasis. These results should encourage future research and GEM studies on FFPE tissue from the invaluable biobanks available at the departments of pathology worldwide.
\end{abstract}

\section{Introduction}

In the last decade, GEM studies have proven valuable in clinical and molecular genetics research. The application of microarrays and transcript profiling analysis in cancer research has been useful in providing insight into the mechanisms and targets involved in oncogenesis $[1,2]$. Additionally, the GEM method has become useful in the prediction of diseases, the prediction of drug responses, and tumor classification. Thus far, the use of GEM has been limited by the need for fresh frozen (FF) materials. Until now, purification of high-quality RNA from FF sample specimens has been considered a prerequisite for microarray analysis. The existing GEM studies have also been restricted to fairly frequent diseases to ensure a sufficient amount of sample material. Collaboration between investigators to overcome the issue of sample size has been hindered mainly by logistic problems, namely, possible exposure of FF material to RNA degradation when freezing is somehow compromised during transport and the subsequent processing of the tissue.

During the last century, tissue biopsies worldwide have routinely been subjected to formalin-fixation and paraffinembedding by pathologists, resulting in large stocks of biopsy materials. Formalin-fixed, paraffin-embedded (FFPE) samples are easy to handle and store and are suitable for diagnostic histology, immunohistochemistry, and in situ hybridization. Therefore, this sample type is almost always available for diseases in which treatment involves surgery to remove parts of or almost the entire affected organ. Furthermore, invaluable clinical information and follow-up data are often accessible in conjunction with FFPE samples [3]. Lastly, the tissue is usually available in amounts adequate for use in GEM studies.

A well-known obstacle in the use of these samples in gene expression analysis has been the extensive degradation, 
fragmentation, and chemical modification of RNA that occur during the fixation process $[4,5]$. However, several recent findings indicate that reverse transcription PCR (RT-PCR) and quantitative PCR (qRT-PCR) on FFPE RNA can produce reliable and reproducible results [6-9].

Nevertheless, gene expression analysis on multiple gene sets is more scarce and has proved more challenging for FFPE samples than for FF samples, especially with regard to the subsequent data analysis and its interpretation $[10,11]$. This issue has been addressed by comparing FF and FFPE samples originating from the same biopsy, but this approach requires that the surgeons, pathologists, or lab technicians have control of the tissue, which implies tissue handling and treatment that differ from the handling of routine samples [12-14]. Some studies overcome this obstacle by comparing the transcription profiles of unmatched FF and FFPE samples, but this approach leads to difficulties in validating the results of the data analysis [15]. However, a few studies solely investigated FFPE samples from patients for tumor classification without the inclusion of healthy control samples $[16,17]$.

$\mathrm{CHI}$ and insulinomas are characterized by hyperinsulinemic hypoglycemia, a condition of low blood glucose due to excessive and uncontrolled endogenous insulin secretion.

$\mathrm{CHI}$ is a monogenic, heterogeneous disease occurring in newborns with dysregulated hypersecretion of insulin, leading to severe hypoglycemia [18]. Currently, disease-causing mutations in seven different genes expressed in pancreatic beta cells are known and account for approximately 50\% of CHI cases [18-25]. Depending on the underlying genetic cause, newborns can either be treated nutritionally and/or medically or require partial or subtotal pancreatectomy [26]. In children requiring subtotal pancreatectomy, postoperative hypoglycemia and in later years diabetes mellitus or impaired glucose tolerance may occur. Gaining more insight into the disease-causing mechanisms in $\mathrm{CHI}$ patients with unknown genetic cause may open new possibilities for medical treatment of beta-cell diseases. Consequently, CHI is one of several relatively rare diseases that would benefit from the use of FFPE tissues in GEM studies.

Insulinomas are pancreatic neuroendocrine tumors that, like the pancreas in CHI patients, produce and secrete insulin at low blood glucose levels. Five to ten percent of all insulinomas are due to mutations in the tumor suppressor gene MEN1 [27]. Insulinomas are usually discovered because they cause hypoglycemic symptoms and need to be differentiated from other conditions that cause fasting hypoglycemia, such as $\mathrm{CHI}[28]$.

In the absence of readily available FF pancreatic tissue samples from healthy controls and patients with $\mathrm{CHI}$, we considered the use of archived FFPE tissue for GEM analyses. In doing so, we would overcome the most prominent challenges regarding relatively rare diseases: the acquisition of the necessary amounts of samples to ensure adequate sample size, the availability of tissue from healthy controls, and the considerably reduced timeline for the study.

In selecting pancreatic tissue for our study, we also indirectly address the issue of whether the results are applicable to other diseases and tissues. Pancreatic tissue presents an
TABLe 1: Sample overview. Overview of the pancreatic samples included in the study: $\mathrm{CHI}$ no. 1-5 were archived, FFPE CHI samples; CHI no. 6-7 were FF CHI samples; samples C no. 1115 were age-appropriate, FFPE pancreatic control samples that had died of not pancreas-related diseases; C no. 16-18 were from an insulinoma that was FF (C no. 18) and FFPE (C no. 16-17).

\begin{tabular}{ccccc}
\hline \multicolumn{2}{c}{ CHI patients } & \multicolumn{2}{c}{ Insulinoma (same biopsy) } & $\begin{array}{c}\text { Neonate } \\
\text { controls }\end{array}$ \\
FFPE & Frozen & FFPE & Frozen & FFPE \\
\hline CHI no. 1 & CHI no. 6 & C no. 16 & C no. 18 & C no. 11 \\
CHI no. 2 & CHI no. 7 & C no. 17 & & C no. 12 \\
CHI no. 3 & & & & C no. 13 \\
CHI no. 4 & & & & C no. 14 \\
CHI no. 5 & & & & C no. 15 \\
\hline
\end{tabular}

extraordinary challenge because it contains high amounts of ribonucleases. The function of ribonucleases in tissue is to degrade RNA; greater amounts of ribonucleases result in faster degradation of RNA. Therefore, the tissue to be investigated is an important aspect in GEM studies, and a successful assessment of pancreatic tissue would undoubtedly be of great interest. According to EPConDB, currently, only 105 GEM studies on pancreatic tissue have been described; these studies have used pancreatic cell lines, pancreas from animal models, and FF human pancreatic tissue [29-32]. As yet, no GEM studies have been conducted on FFPE pancreatic tissue.

Our aim was to assess whether archived, routine-treated FFPE material can be used to gather disease-specific information and whether this usage is also applicable to pancreatic tissue.

\section{Materials and Methods}

2.1. Samples. A total of 15 samples were included in this study (Table 1).

Seven of these were CHI pancreatic samples originating from near-total resections (CHI no. 1-7), of which there were five FFPE pancreatic tissue samples (CHI no. 1-5) and two frozen pancreatic tissue samples (CHI no. 6-7). These seven samples were from independent, unrelated patients. Using methods described earlier by Hussain et al. (2005), no mutations were found in the $\mathrm{CHI}$ samples in the most frequently mutated genes, $A B C C 8$ and KCNJ11 [33]. The control pancreatic tissue samples consisted of five FFPE neonate samples (C no. 11-15) obtained from departmental archives. These neonate samples were obtained from deceased neonates whose deaths were not pancreas related. Further, a neonate insulinoma biopsy was included, in which one portion where one part was originally formalin fixed and paraffin embedded ( $\mathrm{C}$ no. 16 and $\mathrm{C}$ no. 17 ) and the other portion was fresh frozen at $-80^{\circ} \mathrm{C}(\mathrm{C}$ no. 18). Tissues were formalin fixed and paraffin embedded according to standard procedures in the respective departments at the time of surgery.

The samples were obtained from Great Ormond Street Hospital for Children, London, England, and the Department of Clinical Pathology and Department of Pediatrics, University Hospital of Odense, Denmark. Approvals were 
obtained from the ethics committees of Great Ormond Street Hospital for Children, the NHS, Trust and the Institute of Child Health, London; the local ethics committee of Funen and Vejle County, The Danish National Committee on Biomedical Research Ethics; the Danish Data Protection Agency, Denmark. Written informed consent was obtained from the parents or guardians.

2.2. RNA Extraction. Paraffin blocks of FFPE pancreatic samples were cut in two $10 \mu \mathrm{m}$ sections. To extract RNA from FFPE pancreatic sections, paraffin was solubilized with xylene and centrifuged to pellet tissue from the solution. Residual xylene was removed by two ethanol rinses, and the tissue pellet was air dried. The pellet was digested with Proteinase $\mathrm{K}$ overnight in digestion buffer. TRIzol Reagent (Carlsbad, CA, USA) was used to isolate RNA. The final pellets were resuspended in $15 \mu \mathrm{L}$ of nuclease free water and stored at $-80^{\circ} \mathrm{C}$. RNA from frozen pancreatic samples was extracted from 50-100 mg of tissue. The tissue was homogenized and total RNA was extracted using TRIzol Reagent. Samples were stored at $-80^{\circ} \mathrm{C}$

For within-array normalization, we used reference RNA from cell lines. Four different cancer cell lines were included in the reference: HeLa (cervical epithelium), SK-BR-3 (mammary gland), HT29 (colon), and A431 (skin) cells. Cells were grown according to instructions from the American Type Culture Collection (ATCC, Manassas, VA, USA). Total RNA was extracted using an RNeasy Midi Kit (Qiagen, MD, USA).

Subsequently, DNase treatment was then performed on all samples. RNA integrity and concentration were determined with an Agilent Technology Bioanalyzer 2100 (Agilent,z Lindenhurst, NY, USA), and $\mathrm{OD}_{260}$ measurements were obtained.

2.3. Amplification and Labeling. Amplification of DNasetreated samples was performed using an Amino Allyl MessageAmp aRNA kit (Ambion, Austin, TX, USA). Reference RNA was amplified with one round of amplification, whereas the pancreatic samples (FF and FFPE) were subjected to two rounds of amplification. Aminoallyl-modified RNA (aaRNA) from pancreatic samples was labeled with Cy5, and aaRNA from reference cell lines was labelled with Cy3 (Amersham Biosciences, Buckinghamshire, England). Frozen pancreatic samples and reference samples were fragmented using RNA fragmentation reagents (Ambion, Austin, TX, USA) according to the manufacturer's instructions. Fragmented reference aaRNA was subsequently aliquoted.

Two micrograms of labeled pancreatic aaRNA, corresponding to approximately 200 pmol of incorporated dye and $1 \mu \mathrm{g}$ of reference aaRNA, corresponding to approximately 100 pmol incorporated dye, were used for hybridization to the microarray slide.

2.4. Hybridization to and Scanning of Microarray Slides. Oligonucleotide targets $(29,134$ total) were spotted and prepared as previously described [34]. The dried slides were stored in desiccators until use. Hybridization of samples and reference aaRNA and the subsequent microarray washes were performed using an Agilent Gene Expression Hybridization
Kit according to the manufacturer's protocol. Slides were scanned using an Agilent G2565BA microarray scanner (Agilent Technology).

2.5. Data Preprocessing. Spot intensities measured for references and samples were corrected for local background intensities. Data analysis was performed using the variance stabilization normalization procedure $(v s n)$ implemented in the R-based Bioconductor package (http://.org/www.bioconductor.org/) $[35,36]$. A ratio of the normalized intensities was calculated for each spot. Finally, a geometric mean was calculated for the ratios of each pair of spot duplicates and was used as the gene expression measurement. Data are available from GEO (http://www.ncbi.nlm.nih.gov/geo/, Accession no. GSE32610).

\subsection{Data Analysis}

2.6.1. Correlation Analysis. The normalized gene intensities for the Cy3 and Cy5 dyes were compared for labeling efficiencies and reproducibility across all genes by calculating the Pearson correlation coefficient:

$$
\mathrm{CC}=\frac{\sum\left(x-x_{\text {mean }}\right)\left(y-y_{\text {mean }}\right)}{\sqrt{\sum\left(x-x_{\text {mean }}\right)^{2}\left(y-y_{\text {mean }}\right)^{2}}},
$$

where $x$ and $y$ are normalized gene intensities for Cy3 and Cy5 dyes in the log scale.

2.6.2. Cluster Analysis. Unsupervised hierarchical cluster analysis was first applied to all of our genes without filtering to determine whether RNA from FFPE samples contained disease-specific information that could be retrieved. Cluster analysis was then applied to the genes identified as significant to reveal the disease-dependent expression patterns of these genes.

2.6.3. GEE Model. Because the 3 arrays for insulinoma (C no. 16-C no. 18) were from the same biopsy, we introduced the generalized estimation equation (GEE) model to identify genes differentially expressed between CHI patients (FFPE) and the insulinoma case. The GEE model accounts for the correlation in the three arrays with an exchangeable working correlation matrix. The false discovery rate was calculated to adjust for multiple testing.

2.6.4. SAM Analysis. The popular SAM method [37], a penalized $t$-test, was used to compare the gene expression levels between CHI patients (FFPE) and the neonate controls. Different from the standard $t$-test, SAM reduces the effects of noisy genes and evaluates the statistical significance of each gene by a permutation test that accounts for multiple testing. We used 1000 replicates for the permutation test.

\section{Results}

We extracted total RNA from five FFPE CHI samples and five FFPE control samples (Table 1). In addition, RNA was 
harvested from one frozen insulinoma sample with two matched FFPE insulinoma samples obtained from the same pancreas.

Total RNA from FFPE specimens was purified from FFPE pancreas sections with acceptable yields and $\mathrm{OD}_{260 / 280}$ ratios (Table 2) despite extensive degradation (data not shown).

The mean purities $\left(\mathrm{OD}_{260 / 280}\right)$ of total RNA for FFPE and FF were 1.84 and 1.77 , respectively. The RNA yield ranged from $9 \mu \mathrm{g}$ to $77 \mu \mathrm{g}$ (mean $25 \mu \mathrm{g}$ ). The three frozen samples had intact $18 \mathrm{~S}$ and $28 \mathrm{~S}$ ribosomal bands, whereas the FFPE samples did not. RNAs yields were not comparable between frozen and FFPE samples, because frozen tissue was not consistent with the FFPE sections. Because of the obvious differences in RNA quality, dye incorporation rates were of interest. We could not detect differences in incorporation rates: we measured 39.7 and 43.7 dye mols/1000 nts, respectively. Ambion recommended incorporation rates of 30 to 60 dye mols/1000 nts. Thus, despite extensive degradation in FFPE samples, the dye incorporation rates were within the manufacturer's recommendations. We also wished to estimate the reproducibility of the gene expression profiles of pancreatic tissue, particularly because of its high ribonuclease content. For this purpose, we included pancreatic samples that had been routinely both FF, and formalin fixed and paraffin embedded. The pancreatic biopsy was from a child with insulinoma, which fulfilled our criteria. Microarray analysis of the FFPE biopsy was performed in duplicate (C no. 16, C no. 17). The resulting three samples (including the FF insulinoma sample (C no. 18)) were normalized.

In Figure 1(a), the correlation between the $\log _{2}$ signal intensities of Cy3 (reference RNA) and Cy5 (sample RNA) is presented. Keeping in mind that the reference and sample RNAs were not obtained from the same material, the plot does not detect differentially expressed genes between samples. The plots show sample uniformity, which is also supported by their respective correlation coefficients (CC) $\left(\mathrm{CC}_{\mathrm{AI}}: 0.85, \mathrm{CC}_{\mathrm{AII}}: 0.81\right.$, and $\left.\mathrm{CC}_{\mathrm{AIII}}: 0.82\right)$, indicating high comparability between samples despite differences in initial treatment and storage. In addition, to detect eventual intensity-dependent patterns that are likely to be introduced in microarray experiments, the correlation between $\log _{2}$ mean (Cy5/Cy3) versus ratio (Cy5/Cy3) signal intensities is shown in Figure 1(b). The data were distributed horizontally around 0 , indicating that the detected intensities are likely to be of biological origin and not introduced during the laboratory work. The $\mathrm{CC}_{\text {reprod_FFPE }}$ for the two FFPE samples was 0.86 , whereas $\mathrm{CC}_{\text {reprod_FF_FFPE }}$ for the FFPE and FF tissues was 0.63 (for both $C$ no. 16 and $C$ no. 17 versus $C$ no. 18), demonstrating that the two FFPE samples correlated better than frozen and FFPE.

We used a housekeeping gene, GAPDH, as another variable to evaluate reproducibility. GAPDH is arrayed 304 times in duplicate on each microarray slide and is therefore useful for assessing sample- and intraslide variation (Figure 2). Ratios of the expression values of $\mathrm{Cy} 5$ and $\mathrm{Cy} 3$ suggest a slight increase in the number of outliers in FFPE samples compared to FF samples.

Using all the 29214 genes without filtering, we first applied unsupervised hierarchical clustering analysis to the five FFPE controls and five FFPE CHI samples, to see, if the samples contained information that could be used to retrieve their disease status. The dendrogram in Figure 3 showed that four of five $\mathrm{CHI}$ samples clustered as one cluster. The controls clustered in two clusters indicating the usefulness of FFPE samples in a disease study.

We also performed two different gene expression analyses on the normalized data. In the first analysis, we compared five FFPE controls with five FFPE CHI samples using the SAM approach; in the second analysis, we compared three insulinoma samples with five FFPE CHI samples using the GEE model because the three insulinoma samples were correlated.

The QQ-plot in Figure 4 shows the observed versus expected scores for comparing FFPE controls and FFPE $\mathrm{CHI}$ samples. The red and green spots that deviate from the straight line represent genes that were up- and downregulated, respectively. The pattern in Figure 4 shows that our FFPE samples can be used for microarray analysis to identify genes that are differentially expressed under disease conditions. Figure 5 is a heat map displaying the expression patterns for the 19 most highly significant genes. Unsupervised hierarchical clustering applied on the 19 genes clustered four of the five $\mathrm{CHI}$ samples to a branch distinct from the control samples (Figure 5).

The 19 most significantly up- or downregulated genes were further characterized for their functional or biological relevance to congenital hyperinsulinism (Table 3 ).

Hypothetical proteins and genes of unknown function are present in the list. Furthermore, five genes are cancerrelated (PLCXD1, ERBB3, ARPC5L, CBLL1, and PLXDC2), and one is involved in inflammation and immunity (IL1A). Two genes are involved in metabolism; PFKL is involved in glycolysis, and GOT1 is involved in amino acid metabolism [38-45].

Figure 6 is a heat map of 54 significant differentially expressed genes (FDR $<1 \times 10^{-5}$, fold change $>4$ ) in insulinoma and CHI samples that were identified using the GEE model. Unsupervised hierarchical clustering showed a clear separation of the insulinoma and CHI samples. A list of the 54 significantly up- or downregulated genes is presented in Table 4.

Again, hypothetical proteins, genes of unknown function, and cancer-related genes were detected, but most importantly, we detected three genes involved in glycolysis (PFKL, SUCLG2, PFKP) and 2 genes involved in calcium ion homeostasis (CALB2, NUCB2) [42, 46-49].

\section{Discussion}

We show that routine, archived FFPE tissue contains valuable biological and disease-specific information that can be assessed by GEM. The resultant data are amenable to statistical analysis and can give biological and disease-specific information. This finding applies to pancreatic tissue, whose RNA is considered more prone to degradation and fragmentation than RNA from other tissues due to high quantities of ribonucleases, which is of great interest. 
TABLE 2: Total RNA after DNase treatment and labelling with fluorophore. RNA quality and labelling efficiency were calculated for FF and FFPE samples (nt nucleotides, aaRNA aminoallyl-modified RNA).

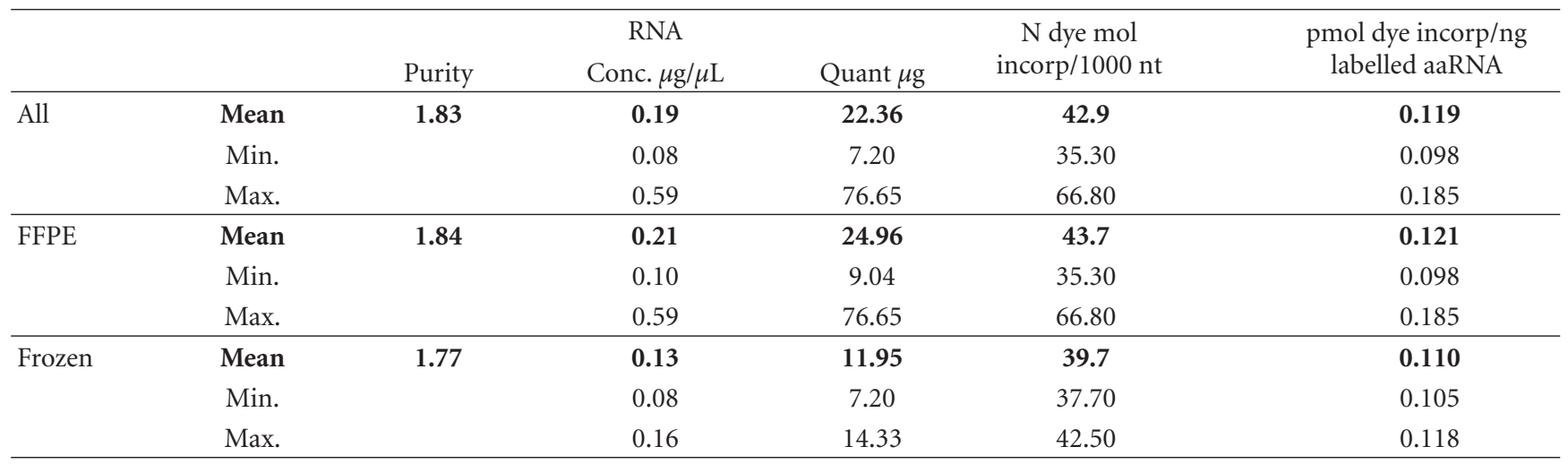
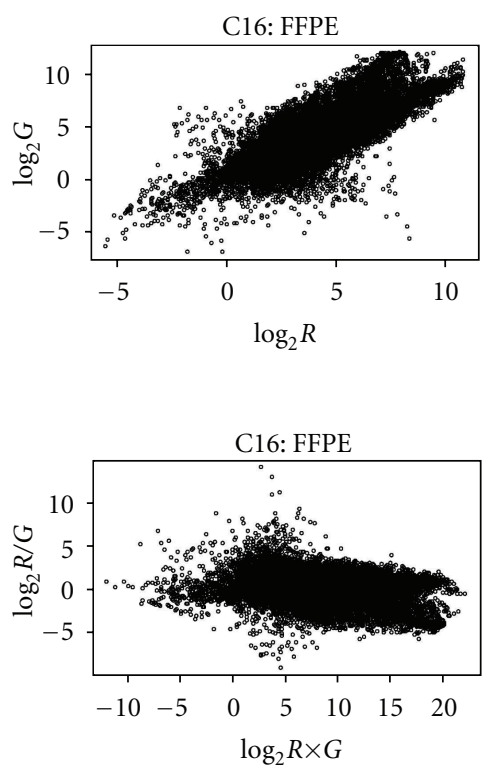

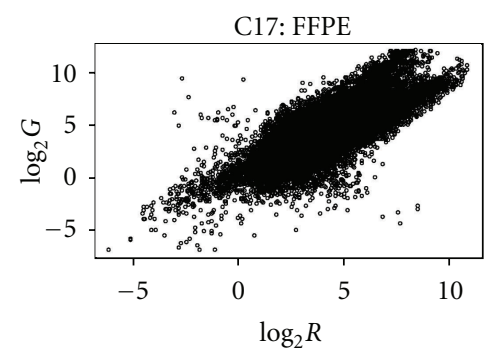

(a)
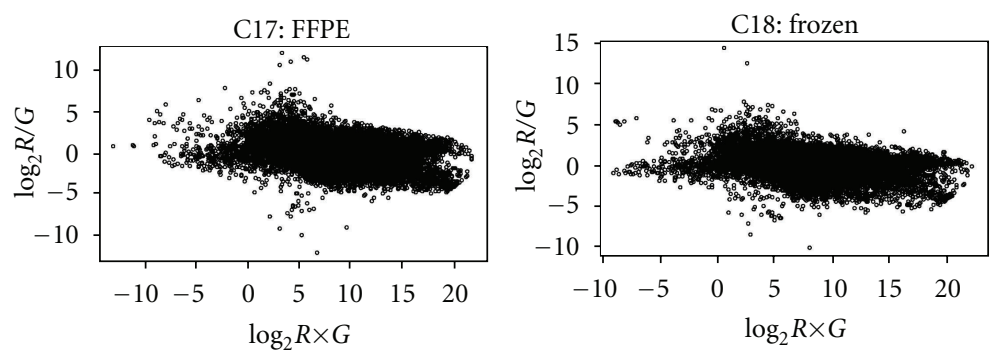

(b)

FIGURE 1: Scatter plot of the $v s n$-normalized and $\log _{2}$-transformed signal intensities. (a) Scatter plot of the $\log _{2}$-transformed signal intensities of insulinoma samples (Cy5) and reference material (Cy3). Correlation coefficient (CC) for each scatter plot (sample versus reference material) is shown on the top, confirming the very uniform spot distribution. (b) Scatter plot of the $\log _{2}$-transformed signal intensities: square root of sample multiplied reference ( $y$-axes) against ratio of sample versus reference ( $x$-axes). The data distribute around a horizontal line at $0 . \mathrm{CC}_{\text {reprod_FFPE }}$ for the two FFPE samples was 0.86, whereas $\mathrm{CC}_{\text {reprod_FF_FFPE }}$ for FF and FFPE tissues was 0.63 .

This pilot study was conducted to determine whether FFPE pancreatic tissue is amenable to GEM. We included seven CHI pancreatic samples in the study with unknown genetic causes that are not likely to be of the same genetic origin. To date, clinicians have been unable to subdivide these unexplained individuals into groups according to clinical and/or biochemical features. Our group of CHI samples was therefore likely to be genetically different by chance alone. Despite this assumed genetic heterogeneity, in this study, we were able to show that ribonuclease-rich FFPE tissue contains biological information that can be retrieved. We were able to separate the samples according to disease, thereby demonstrating that the interesting disease-specific information was still present in the RNA of the samples.
Also, we detected cancer-related genes, which could be related to the hypertrophy occurring in $\mathrm{CHI}$ pancreatic islets. The assumed genetic heterogeneity could explain the broad spectrum of cancer-related genes we detected. Additionally, we also identified significantly differentially expressed genes that are involved in glycolysis (PFKL, SUCLG2, and PFKP) and calcium-homeostasis (CALB2 and NUCB2). Glycolysis and calcium-homeostasis are two important steps in the regulation of insulin synthesis and secretion $[46,49,50]$.

To our knowledge, thus far, there have not been any studies performed on FFPE tissue in which this tissue type was also chosen as the control with the overall purpose of narrowing down potential disease-relevant pathways. Similar studies have been performed on FF tissue with good results 
TABLE 3: List of 19 significantly up- and downregulated genes. List of significantly differentially up- and downregulated genes in FFPE CHI versus FFPE control samples. Genes are listed according to the heat map in Figure 5.

\begin{tabular}{|c|c|c|c|}
\hline Symbol & Gene & Function & Reference \\
\hline PLCXD1 & Hypothetical protein FLJ11323 & Intracellular signaling cascade & [38] \\
\hline BC028018 & Similar to serine/arginine repetitive matrix 1 & Unknown & \\
\hline ERBB3 & v-erb-b2 erythroblastic leukemia viral oncogene homolog 3 (avian) & Proteolysis and peptidolysis & [39] \\
\hline ARPC5L & $\begin{array}{l}\text { Hypothetical protein similar to actin related protein } 2 / 3 \text { complex, } \\
\text { subunit } 5\end{array}$ & Cell motility & {$[40]$} \\
\hline IL1A & Interleukin 1, alpha & Physiological processes & [41] \\
\hline AJ131610 & Trapped putative $3^{\prime}$ terminal exon, clone D2C3. & Unknown & \\
\hline NOX3 & NADPH oxidase 3 & Electron transport & \\
\hline BC035836 & Similar to Lysophospholipase, clone IMAGE:5589106 & Amino acid metabolism & \\
\hline CRFG & G protein-binding protein CRFG & Oxygen transport & \\
\hline PFKL & Phosphofructokinase, liver & Glycolysis & [42] \\
\hline MGC33309 & Hypothetical protein MGC33309 & Physiological processes & \\
\hline UBE2M & Ubiquitin-conjugating enzyme E2M (UBC12 homolog, yeast) & Physiological processes & \\
\hline PLXDC2 & Tumor endothelial marker 7-related precursor & Development & [43] \\
\hline B3GALT1 & UDP-Gal:betaGlcNAc beta 1,3-galactosyltransferase, polypeptide 1 & Physiological processes & \\
\hline CBLL1 & E-cadherin binding protein E7 & $\begin{array}{l}\text { Regulation of transcription, DNA } \\
\text { dependent }\end{array}$ & {$[44]$} \\
\hline GOLPH4 & Golgi phosphoprotein 4 & Central nervous system development & \\
\hline KIAA0319 & KIAA0319 gene product & Blood coagulation & \\
\hline CSN10 & Casein, kappa & Physiological processes & \\
\hline GOT1 & $\begin{array}{l}\text { Glutamic-oxaloacetic transaminase } 1 \text {, soluble (aspartate } \\
\text { aminotransferase 1) }\end{array}$ & Amino acid metabolism & {$[45]$} \\
\hline
\end{tabular}

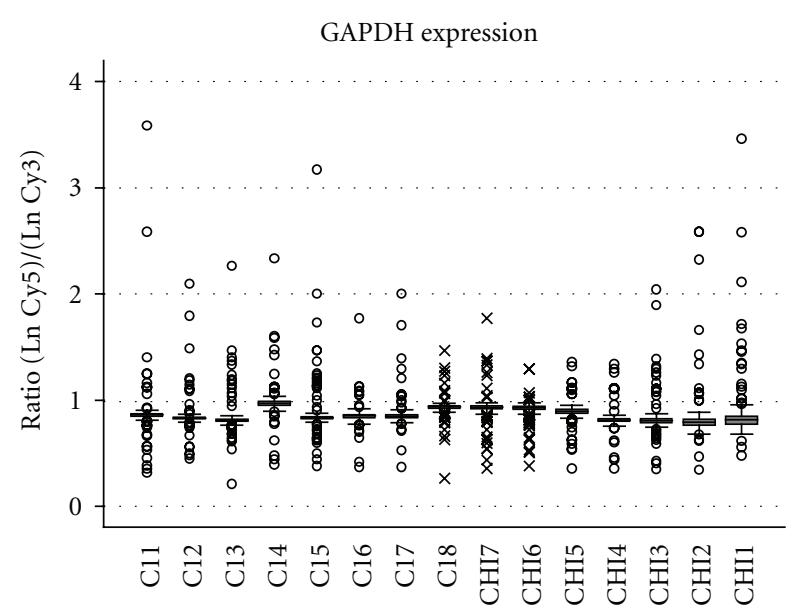

Figure 2: Normalized GAPDH intensities for all samples. GAPDH was arrayed 304 times on every slide. The mean and percentiles results for GAPDH on all slides. Expression values are plotted as the ratio of Ln sample (Cy5) versus Ln reference material (Cy3). FFPE samples are marked $\circ$, whereas frozen samples are marked $\times$. Spot outliers are seen for all samples but more pronounced in FFPE samples.

[51-53]. Studies based on FFPE tissue mostly address issues such as whether (a) matched FF and FFPE RNA in GEM produce the same GEM results, depending on the laboratory and data analysis methods used $[11,14,15,54-56]$ or (b)

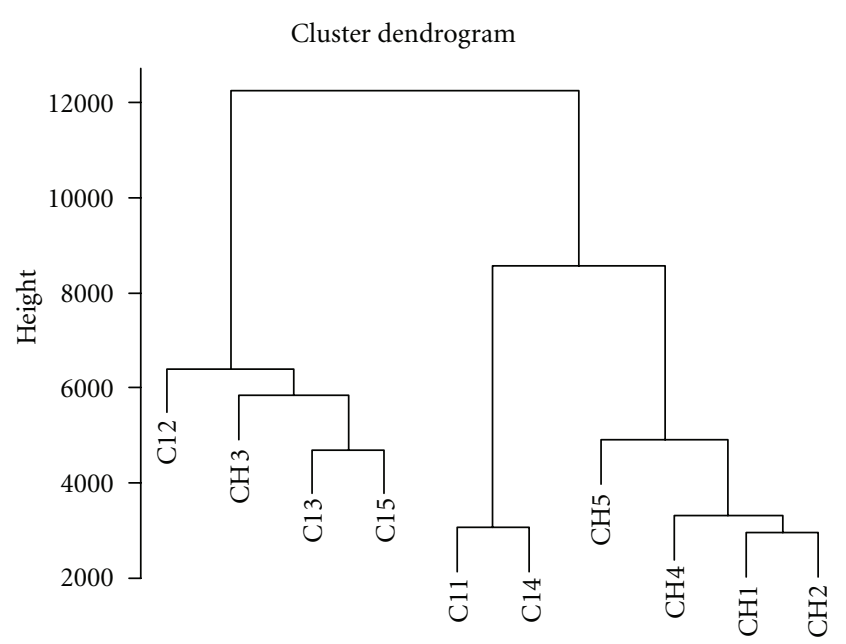

FIGURE 3: Unsupervised hierarchical clustering. Unsupervised hierarchical cluster analysis on all 29214 without filtering applied to the five FFPE controls and five FFPE CHI samples. Four of five $\mathrm{CHI}$ samples cluster together in a subcluster.

FFPE samples can be used for tumor classification [57]. Hoshida et al. (2008) used FFPE liver tissue to produce a signature model to predict survival in hepatocellular carcinomas [17].

Jacobson et al. (2011) presented a gene expression study that included tissue harvested from non-small-cell 
TABLE 4: List of 54 significantly up- and down- regulated genes. List of significantly differentially down- and up regulated genes of insulinoma versus CHI samples. Genes are listed according to the heat map in Figure 6. Above the line are the genes downregulated in CHI samples compared to insulinoma.

\begin{tabular}{|c|c|c|c|}
\hline Symbol & Gene & Function & Reference \\
\hline KIAA0102 & KIAA0102 gene product & Development & \\
\hline PRY & PTPN13-like, Y-linked & Unknown & \\
\hline RASSF1 & Ras association (RalGDS/AF-6) domain family 1, transcr. var. D & Intracellular signaling cascade & \\
\hline SF3B1 & Splicing factor $3 \mathrm{~b}$, subunit $1,155 \mathrm{kDa}$ & mRNA splicing & \\
\hline PFKL & Phosphofructokinase, liver & Glycolysis & {$[42]$} \\
\hline TRIM15 & Tripartite motif-containing 15 , transcript variant 2 & Mesoderm cell fate determination & \\
\hline CALB2 & Calbindin 2, $29 \mathrm{kDa}$ (calretinin), transcript variant CALB2 & Calcium ion homeostasis & {$[46]$} \\
\hline CAPS2 & Calcyphosphine 2 & Intracellular signaling cascade & \\
\hline \multirow[t]{2}{*}{ SUCLG2 } & Succinate-CoA ligase, GDP-forming, beta-subunit & Glycolysis & {$[47]$} \\
\hline & DKFZP566F0546 protein & Metabolism & \\
\hline \multirow[t]{2}{*}{ MYOM2 } & Myomesin (M-protein) 2, $165 \mathrm{kDa}$ & Striated muscle contraction & \\
\hline & Similar to RIKEN cDNA 1110018M03, complete cds & Mesoderm cell fate determination & \\
\hline \multirow[t]{2}{*}{ APOL4 } & Apolipoprotein $\mathrm{L}, 4$, transcript variant a & Lipid transport & \\
\hline & cDNA FLJ39458 fis, clone PROST2011297 & Unknown & \\
\hline WIG1 & P53 target zinc finger protein, transcript variant 1 & RNA processing & \\
\hline HSPC228 & Hypothetical protein HSPC228 & Chemotaxis & \\
\hline \multirow[t]{2}{*}{ COG7 } & Component of oligomeric golgi complex 7 & N-linked glycosylation & \\
\hline & mRNA for KIAA1199 protein, partial cds. & N-linked glycosylation & \\
\hline \multirow[t]{2}{*}{ FLII } & Flightless I homolog (Drosophila) & Development & \\
\hline & Human 12-lipoxygenase, partial cds. & Electron transport & \\
\hline \multirow[t]{2}{*}{ PFKP } & Phosphofructokinase, platelet & Glycolysis & {$[48]$} \\
\hline & Clone MGC: 4267 IMAGE: 3531734, complete cds. & $\begin{array}{l}\text { Negative regulation of transcription from } \\
\text { polymerase II promoter }\end{array}$ & \\
\hline CRMP5 & Collapsin response mediator protein-5; CRMP3-assoc. molec. & Nitrogen metabolism & \\
\hline SEC8 & Secretory protein SEC8 & Golgi to plasma membrane transport & \\
\hline EML1 & Echinoderm microtubule associated protein like 1 & Physiological processes & \\
\hline FPR1 & Formyl peptide receptor 1 & Chemotaxis & \\
\hline C20orf172 & Chromosome 20 open reading frame 172 & Hydrogen transport & \\
\hline WASPIP & Wiskott-Aldrich syndrome protein interacting protein & Cellular morphogenesis & \\
\hline FLJ13868 & Hypothetical protein FLJ13868 & Transport & \\
\hline STAG3 & Stromal antigen 3 & Male meiosis sister chromatid cohesion & \\
\hline FLJ21963 & Hypothetical protein FLJ21963 & Metabolism & \\
\hline \multirow[t]{3}{*}{ RER1 } & Similar to S. cerevisiae RER1 & Retrograde (Golgi to ER) transport & \\
\hline & cDNA FLJ12310 fis, clone MAMMA1001970. & Unknown & \\
\hline & $\begin{array}{l}\text { HSPC182 protein, clone MGC: } 2805 \text { IMAGE: } 2961422 \text {, } \\
\text { complete cds. }\end{array}$ & Amino acid metabolism & \\
\hline GAPDH & Human glyceraldehyde-3-phosphate dehydrogenase & Positive control & \\
\hline SLC11A3 & $\begin{array}{l}\text { Solute carrier family } 11 \text { (proton-coupled dival. metal ion } \\
\text { transp.), member } 3\end{array}$ & Iron ion transport & \\
\hline SERPINI1 & $\begin{array}{l}\text { Serine (or cysteine) proteinase inhibitor, clade I (neuroserpin), } \\
\text { member } 1\end{array}$ & Peripheral nervous system development & \\
\hline AMD1 & S-adenosylmethionine decarboxylase 1 & Amine biosynthesis & \\
\hline NUCB2 & Nucleobindin 2 & Calcium ion homeostasis & {$[49]$} \\
\hline PWP1 & Nuclear phosphoprotein similar to S. cerevisiae PWP1 & Transcription & \\
\hline CCM1 & Cerebral cavernous malformations 1 & Small GTPase mediated signal transduction & \\
\hline $\mathrm{H} 4 \mathrm{FG}$ & H4 histone family, member G & Nucleosome assembly & \\
\hline FLJ11939 & Hypothetical protein FLJ11939 & Neuropeptide signaling pathway & \\
\hline UBE2G2 & Ubiquitin-conjugating enzyme E2G 2 (UBC7 homolog, yeast) & Physiological processes & \\
\hline
\end{tabular}


Table 4: Continued.

\begin{tabular}{lll}
\hline Symbol & Gene & Function \\
\hline CSN10 & Casein, kappa & Physiological processes \\
& $\begin{array}{l}\text { Similar to Lysophospholipase, clone IMAGE: 5589106, partial } \\
\text { cds. }\end{array}$ & Amino acid metabolism \\
& Homo sapiens, clone IMAGE: 4330016 & Unknown \\
TM4SF2 & Transmembrane 4 superfamily member 2 & Cell motility \\
PHC3 & Polyhomeotic like 3 (Drosophila) & Development \\
MLP & MARCKS-like protein & Cell motility \\
& cDNA FLJ37605 fis, clone BRCOC2010510. & Unknown \\
IL1A & Interleukin 1, alpha & Physiological processes \\
GORASP2 & Golgi reassembly stacking protein 2, 55 kDa & Intracellular signaling cascade \\
COX17 & COX17 homolog, cytochrome c oxidase assembly protein & Copper ion transport \\
\hline
\end{tabular}

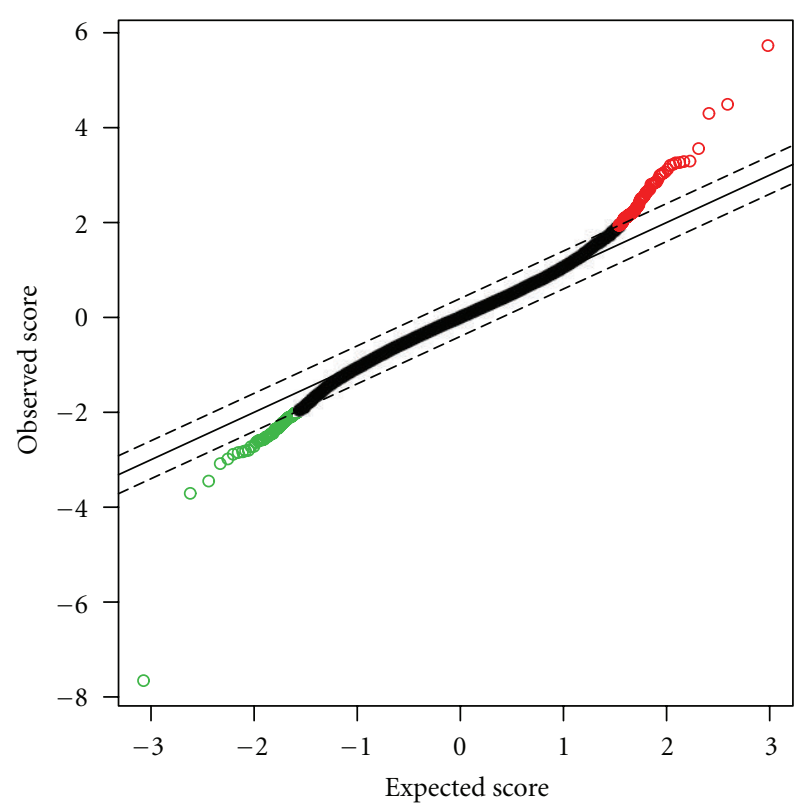

FIGURE 4: QQ plot of observed versus expected score. The QQ plot shows the observed score versus expected score of five FFPE control samples and five FFPE CHI samples. Disease-specific significantly up- and downregulated genes can be detected. Red: upregulated; green: downregulated.

lung cancer. The study addressed two interesting issues: storage time and methodology; the authors concluded that storage time was not a limiting factor for RNA quality and its further applicability, whereas the methods/commercially manufactured kits that were used had varying outcomes. Another approach involved detecting the differences in glioblastoma expression profiles between FF and FFPE samples [55]. FFPE samples expressed a reduced number of significant transcripts compared to FF samples, but the overall expression pattern for the significantly differentially regulated transcripts was similar in the two groups. The use of RNA from FFPE tissue for the identification of differentially expressed genes is supported by Fedorowicz et al.
(2009), whereas Kibriya et al. (2010) advise against it. In general, the use of FFPE tissue in GEM studies is as regarded useful, considering the lack of other options $[11,14]$.

Penland et al. (2007) determined four criteria for RNA quality and quantity to predict which samples would hybridize successfully. We addressed three of the four criteria: (a) a sample purity $\left(\mathrm{OD}_{260 / 280^{-}}\right.$ratio $)>1.5$ of the extracted total RNA, (b) a total RNA yield of $>600 \mathrm{ng}$, and (c) a dye incorporation rate of $>4.5 \mathrm{pmol} / \mathrm{ng}$ in labeled aRNA [57]. Our data fulfilled the first two criteria, whereas our dye incorporation rate was much lower than the recommended limit, with means of 0.11 and $0.21 \mathrm{pmol} / \mathrm{ng}$ for $\mathrm{FF}$ and FFPE samples, respectively. However, the incorporation rates for our samples fulfilled the recommendations of the manufacturer (Ambion). Another approach to determine the quality of the data produced is to compare correlation coefficients. Frank et al. (2007) calculated a $\mathrm{CC}_{\text {reprod }}$ greater than 0.95 after normalization in FFPE samples, whereas directly comparing FF and FFPE replicates resulted in a mean $\mathrm{CC}_{\text {reprod }}$ of 0.86 , which is considered suboptimal by Frank et al. However, our data yielded $\mathrm{CC}_{\text {reprod }}$ values of 0.86 and 0.63 for the two FFPE insulinomas and the FF and FFPE insulinomas, respectively [15]. Despite this discrepancy, we achieved a reasonably good comparability between the FF and FFPE samples, with $\mathrm{CC}_{\mathrm{AI}-\mathrm{AIII}}$ values from 0.81 to 0.85 .

Considering this, our cluster analyses showed that our data were feasible, even though they did not fulfill the criteria stated by Penland et al. (2007) and Frank et al. (2007). Cluster analysis revealed that CHI samples were in a different subcluster separate from both normal controls and insulinoma samples $[15,57]$. The significantly up- and downregulated genes were mostly cancer related but, most importantly, also included genes that are involved in the regulation of insulin synthesis and secretion. CHI is diagnosed histologically as diffuse beta cell abnormality, which supports the finding of cancer-related genes in our analysis. Because $\mathrm{CHI}$ is a congenital disorder in which excessive insulin secretion causes hypoglycemia, the finding of up- and downregulated genes involved in glycolysis (PFKL, SUCLG2, and $P F K P$ ) and calcium ion homeostasis (CALB2, NUCB2) clearly shows that disease-relevant biological information is 


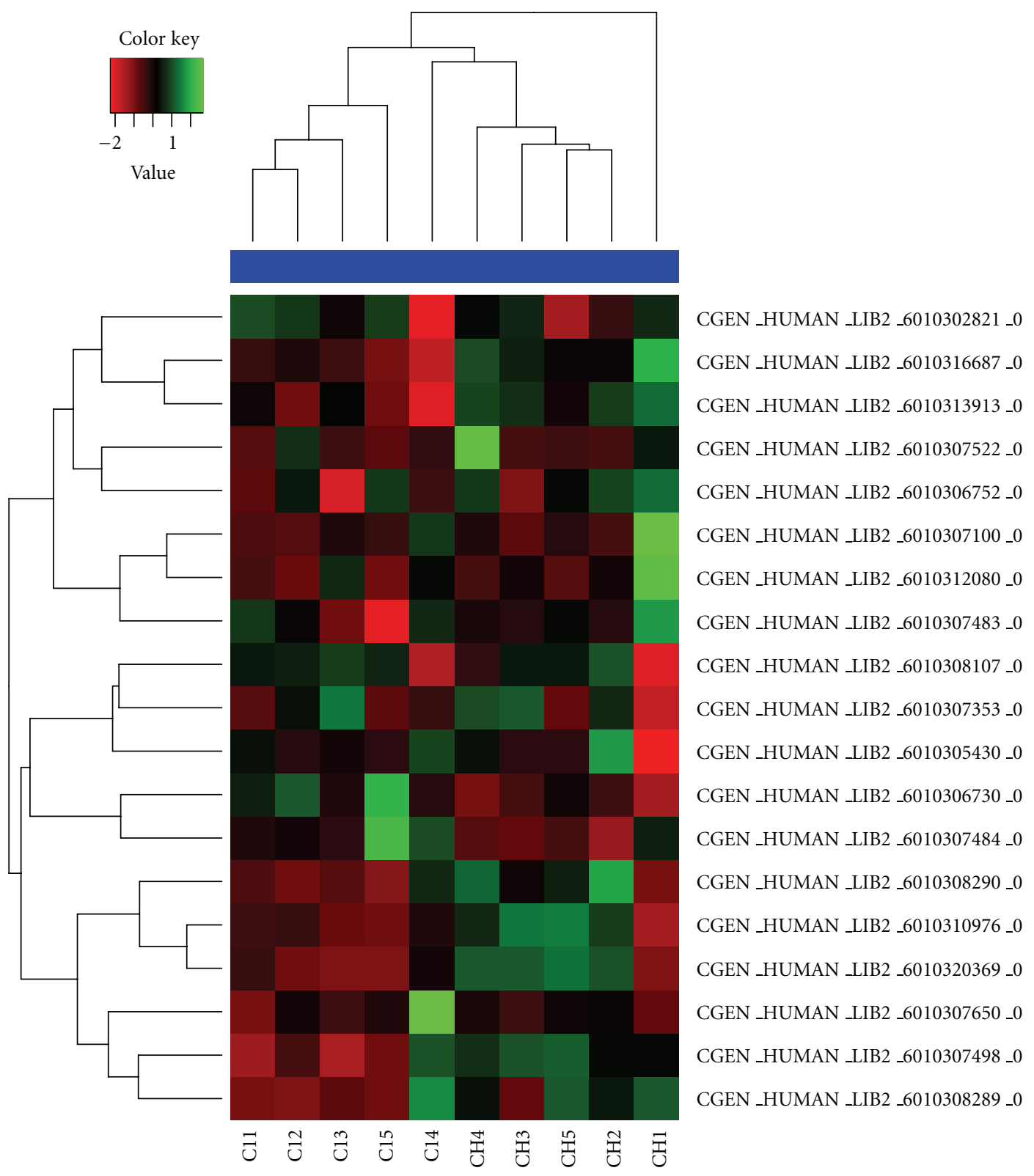

FIGURE 5: Heat map on 19 significantly expressed genes in FFPE samples. Unsupervised hierarchical clustering on 19 significantly differentially expressed genes in the five FFPE controls and five FFPE CHI samples using SAM analysis. Red: downregulation; green: upregulation.

retrievable even from pancreatic FFPE tissue $[46,49,50]$. We do not find significant differential insulin gene expression neither comparing insulinoma and $\mathrm{CHI}$ nor controls with CHI. The reason for this is not clear but could be explained by the insulin-lowering medication prescribed to insulinoma and $\mathrm{CHI}$ patients before surgery. In these patients, the medical effect is not sufficient to treat hyperinsulinemia but might be sufficient to erase significant differential insulin gene expression in $\mathrm{CHI}$ versus controls and $\mathrm{CHI}$ versus insulinoma.

Despite the small sample size and the use of pancreatic tissue, we were able to show that FFPE tissue can be used as a sample source for GEMs. In light of our results and the growing knowledge regarding FFPE tissue, it seems worth- while to study this type of tissue more closely. Future studies should address the issue of how to analyze data from FFPE samples that are not classified together with genetic certainty. Although the laboratory utility of FFPE has been examined from numerous angles, data analysis issues still remain.

\section{Conclusions}

This study shows that ribonuclease-rich pancreatic tissue that has been processed in formalin and paraffin still contains meaningful biological information that can be gathered through GEM studies. The results show that informative hybridizations of archived, FFPE-derived aaRNA produced 


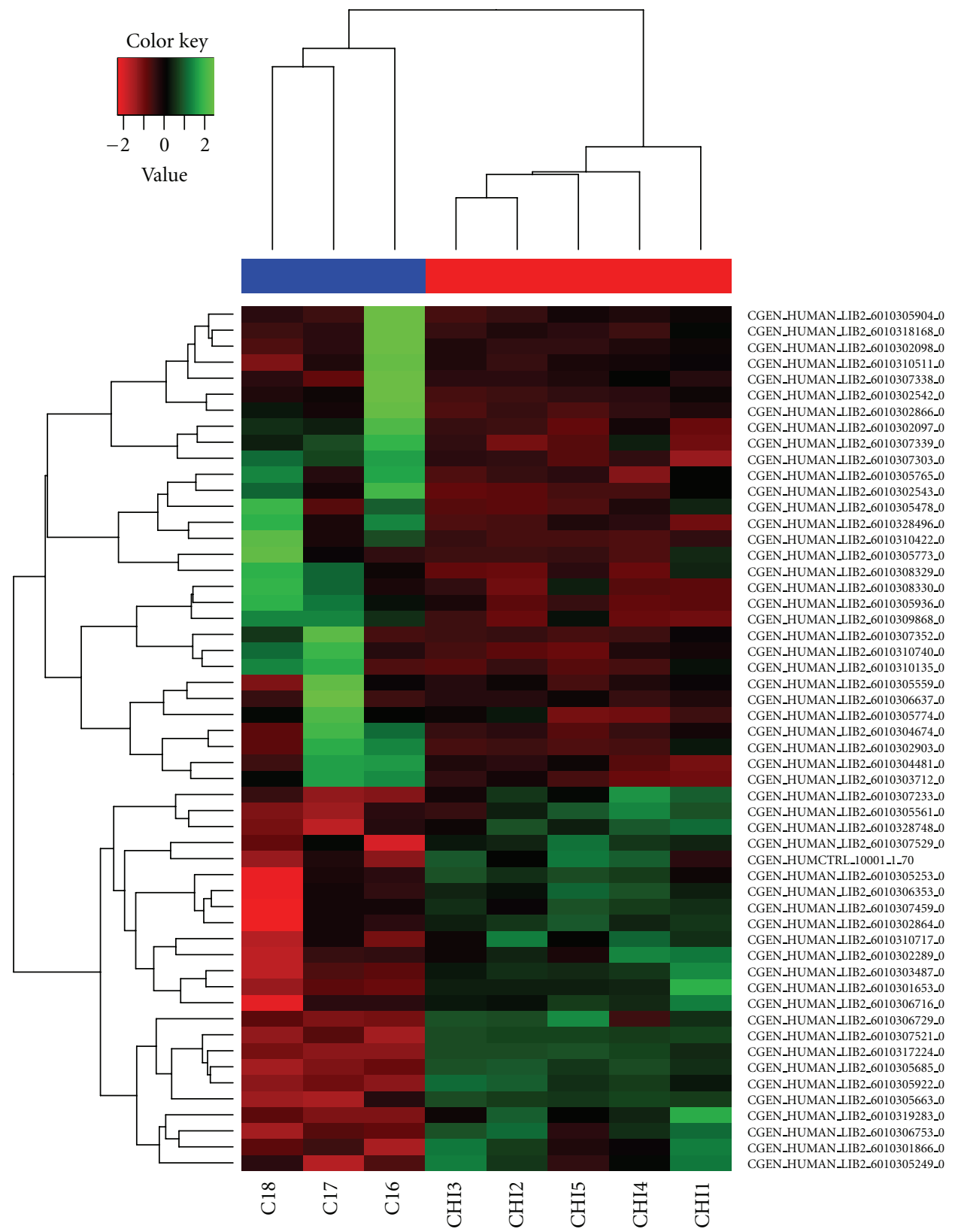

FIGURE 6: Heat map on 54 significantly expressed genes in CHI and insulinoma samples. Unsupervised hierarchical clustering on 54 significant differentially expressed genes in insulinoma and FFPE CHI samples using the GEE model. The analysis separates insulinoma from CHI samples.

expression data of sufficient quality to allow the identification of disease-specific profiles. The findings also indicate that CHI subtypes, distinguished by different disease-causing mutations, can be identified from FFPE tissue.

\section{Conflict of Interests}

The authors declare that they have no competing interests.

\section{Acknowledgments}

The authors thank Professor, M.D., Claus Hovendal, Department of Surgical Gastroenterology, for his cooperation as surgeon and Professor Claus Fenger, Department of Clinical pathology, for providing control samples, both Odense University Hospital, Odense, Denmark. This work was financially supported by Diabetesforeningen, Denmark, Overlægerådets Legatudvalg, Odense University Hospital, Denmark, and Fonden for lægevidenskabelig forskning ved Fyns Amts Sygehusvæsen, Denmark.

\section{References}

[1] E. Segal, N. Friedman, N. Kaminski, A. Regev, and D. Koller, "From signatures to models: understanding cancer using 
microarrays," Nature Genetics, vol. 37, no. 6, supplement, pp. S38-S45, 2005.

[2] B. R. Zeeberg, W. Feng, G. Wang et al., "GoMiner: a resource for biological interpretation of genomic and proteomic data," Genome biology, vol. 4, no. 4, article R28, 2003.

[3] F. Lewis, N. J. Maughan, V. Smith, K. Hillan, and P. Quirke E, "Unlocking the archive-gene expression in paraffin-embedded tissue," Journal of Pathology, vol. 195, no. 1, pp. 66-71, 2001.

[4] N. Masuda, T. Ohnishi, S. Kawamoto, M. Monden, and K. Okubo, "Analysis of chemical modification of RNA from formalin-fixed samples and optimization of molecular biology applications for such samples," Nucleic Acids Research, vol. 27, no. 22, pp. 4436-4443, 1999.

[5] M. Srinivasan, D. Sedmak, and S. Jewell, "Effect of fixatives and tissue processing on the content and integrity of nucleic acids," American Journal of Pathology, vol. 161, no. 6, pp. 19611971, 2002.

[6] J. Finke, R. Fritzen, P. Ternes, W. Lange, and G. Dolken, "An improved strategy and a useful housekeeping gene for RNA analysis from formalin-fixed, paraffin-embedded tissues by PCR," BioTechniques, vol. 14, no. 3, pp. 448-453, 1993.

[7] D. P. Jackson, F. A. Lewis, G. R. Taylor, A. W. Boylston, and P. Quirke, "Tissue extraction of DNA and RNA and analysis by the polymerase chain reaction," Journal of Clinical Pathology, vol. 43, no. 6, pp. 499-504, 1990.

[8] K. Specht, T. Richter, U. Müller, A. Walch, M. Werner, and H. Höfler, "Quantitative gene expression analysis in microdissected archival formalin-fixed and paraffin-embedded tumor tissue," American Journal of Pathology, vol. 158, no. 2, pp. 419 429, 2001.

[9] G. Stanta, S. Bonin, and R. Perin, "RNA extraction from formalin-fixed and paraffin-embedded tissues," Methods in Molecular Biology, vol. 86, pp. 23-26, 1998.

[10] T. E. Godfrey, S. H. Kim, M. Chavira et al., "Quantitative mRNA expression analysis from formalin-fixed, paraffinembedded tissues using $5^{\prime}$ nuclease quantitative reverse transcription-polymerase chain reaction," Journal of Molecular Diagnostics, vol. 2, no. 2, pp. 84-91, 2000.

[11] M. G. Kibriya, F. Jasmine, S. Roy, R. M. Paul-Brutus, M. Argos, and H. Ahsan, "Analyses and interpretation of wholegenome gene expression from formalin-fixed paraffin-embedded tissue: an illustration with breast cancer tissues," BMC Genomics, vol. 11, no. 1, article 622, 2010.

[12] H. N. Abrahamsen, T. Steiniche, E. Nexo, S. J. HamiltonDutoit, and B. S. Sorensen, "Towards quantitative mRNA analysis in paraffin-embedded tissues using real-time reverse transcriptase-polymerase chain reaction: a methodological study on lymph nodes from melanoma patients," Journal of Molecular Diagnostics, vol. 5, no. 1, pp. 34-41, 2003.

[13] C. April, B. Klotzle, T. Royce et al., "Whole-genome gene expression profiling of formalin-fixed, paraffin-embedded tissue samples," PLoS ONE, vol. 4, no. 12, Article ID e8162, 2009.

[14] G. Fedorowicz, S. Guerrero, T. D. Wu, and Z. Modrusan, "Microarray analysis of RNA extracted from formalin-fixed, paraffin-embedded and matched fresh-frozen ovarian adenocarcinomas," BMC Medical Genomics, vol. 2, article 23, 2009.

[15] M. Frank, C. Doring, D. Metzler, S. Eckerle, and M. L. Hansmann, "Global gene expression profiling of formalin-fixed paraffin-embedded tumor samples: a comparison to snapfrozen material using oligonucleotide microarrays," Virchows Archiv, vol. 450, no. 6, pp. 699-711, 2007.
[16] J. Budczies, W. Weichert, A. Noske et al., "Genome-wide gene expression profiling of formalin-fixed paraffin-embedded breast cancer core biopsies using microarrays," Journal of Histochemistry and Cytochemistry, vol. 59, no. 2, pp. 146-157, 2011.

[17] Y. Hoshida, A. Villanueva, M. Kobayashi et al., "Gene expression in fixed tissues and outcome in hepatocellular carcinoma," New England Journal of Medicine, vol. 359, no. 19, pp. 1995-2004, 2008.

[18] A. Aynsley-Green, J. M. Polak, and S. R. Bloom, "Nesidioblastosis of the pancreas: definition of the syndrome and the management of the severe neonatal hyperinsulinaemic hypoglycaemia," Archives of Disease in Childhood, vol. 56, no. 7, pp. 496-508, 1981.

[19] T. Otonkoski, H. Jiao, N. Kaminen-Ahola et al., "Physical exercise-induced hypoglycemia caused by failed silencing of monocarboxylate transporter 1 in pancreatic $\beta$ cells," American Journal of Human Genetics, vol. 81, no. 3, pp. 467-474, 2007.

[20] A. Nestorowicz, B. A. Wilson, K. P. Schoor et al., "Mutations in the sulfonylurea receptor gene are associated with familial hyperinsulinism in Ashkenazi Jews," Human Molecular Genetics, vol. 5, no. 11, pp. 1813-1822, 1996.

[21] P. Thomas, Y. Ye, and E. Lightner, "Mutation of the pancreatic islet inward rectifier Kir6.2 also leads to familial persistent hyperinsulinemic hypoglycemia of infancy," Human Molecular Genetics, vol. 5, no. 11, pp. 1809-1812, 1996.

[22] H. B. T. Christesen, B. B. Jacobsen, S. Odili et al., "The second activating glucokinase mutation (A456V): implications for glucose homeostasis and diabetes therapy," Diabetes, vol. 51, no. 4, pp. 1240-1246, 2002.

[23] P. T. Clayton, S. Eaton, A. Aynsley-Green et al., "Hyperinsulinism in short-chain L-3-hydroxyacyl-CoA dehydrogenase deficiency reveals the importance of $\beta$-oxidation in insulin secretion," Journal of Clinical Investigation, vol. 108, no. 3, pp. 457-465, 2001.

[24] B. Glaser, P. Kesavan, M. Heyman et al., "Familial hyperinsulinism caused by an activating glucokinase mutation," New England Journal of Medicine, vol. 338, no. 4, pp. 226-230, 1998.

[25] C. A. Stanley, Y. K. Lieu, B. Y. L. Hsu et al., "Hyperinsulinism and hyperammonemia in infants with regulatory mutations of the glutamate dehydrogenase gene," New England Journal of Medicine, vol. 338, no. 19, pp. 1352-1357, 1998.

[26] J. B. Arnoux, P. de Lonlay, M. J. Ribeiro et al., "Congenital hyperinsulinism," Early Human Development, vol. 86, no. 5, pp. 287-294, 2010.

[27] E. Batcher, P. Madaj, and A. G. Gianoukakis, "Pancreatic neuroendocrine tumors," Endocrine Research, vol. 36, no. 1, pp. 35-43, 2011.

[28] J. M. Guettier and P. Gorden, "Insulin secretion and insulinproducing tumors," Expert Review of Endocrinology and Metabolism, vol. 5, no. 2, pp. 217-227, 2010.

[29] B. Calderon, J. A. Carrero, M. J. Miller, and E. R. Unanue, "Entry of diabetogenic T cells into islets induces changes that lead to amplification of the cellular response," Proceedings of the National Academy of Sciences of the United States of America, vol. 108, no. 4, pp. 1567-1572, 2011.

[30] C. A. Iacobuzio-Donahue, A. Maitra, G. L. Shen-Ong et al., "Discovery of novel tumor markers of pancreatic cancer using global gene expression technology," American Journal of Pathology, vol. 160, no. 4, pp. 1239-1249, 2002.

[31] C. A. Iacobuzio-Donahue, R. Ashfaq, A. Maitra et al., "Highly expressed genes in pancreatic ductal adenocarcinomas: a 
comprehensive characterization and comparison of the transcription profiles obtained from three major technologies," Cancer Research, vol. 63, no. 24, pp. 8614-8622, 2003.

[32] S. Ogaki, S. Harada, N. Shiraki, K. Kume, and S. Kume, "An expression profile analysis of ES cell-derived definitive endodermal cells and Pdx1-expressing cells," BMC Developmental Biology, vol. 11, article 13, 2011.

[33] K. Hussain, K. E. Cosgrove, R. M. Shepherd et al., "Hyperinsulinemic hypoglycemia in Beckwith-Wiedemann syndrome due to defects in the function of pancreatic $\beta$-cell adenosine triphosphate-sensitive potassium channels," Journal of Clinical Endocrinology and Metabolism, vol. 90, no. 7, pp. 4376-4382, 2005.

[34] M. Thomassen, V. Skov, F. Eiriksdottir et al., "Spotting and validation of a genome wide oligonucleotide chip with duplicate measurement of each gene," Biochemical and Biophysical Research Communications, vol. 344, no. 4, pp. 1111-1120, 2006.

[35] W. Huber, A. Von Heydebreck, H. Sültmann, A. Poustka, and M. Vingron, "Variance stabilization applied to microarray data calibration and to the quantification of differential expression," Bioinformatics, vol. 18, no. 1, supplement, pp. S96-S104, 2002.

[36] W. Shannon, R. Culverhouse, and J. Duncan, "Analyzing microarray data using cluster analysis," Pharmacogenomics, vol. 4, no. 1, pp. 41-52, 2003.

[37] V. G. Tusher, R. Tibshirani, and G. Chu, "Significance analysis of microarrays applied to the ionizing radiation response," Proceedings of the National Academy of Sciences of the United States of America, vol. 98, no. 9, pp. 5116-5121, 2001.

[38] O. Modlich, H. B. Prisack, M. Munnes, W. Audretsch, and H. Bojar, "Predictors of primary breast cancers responsiveness to preoperative epirubicin/cyclophosphamide-based chemotherapy: translation of microarray data into clinically usefull predictive signatures," Journal of Translational Medicine, vol. 3, article 32, 2005.

[39] G. Sithanandam and L. M. Anderson, "The ERBB3 receptor in cancer and cancer gene therapy," Cancer Gene Therapy, vol. 15, no. 7, pp. 413-448, 2008.

[40] P. Klener, M. Szynal, Y. Cleuter et al., "Insights into gene expression changes impacting B-cell transformation: crossspecies microarray analysis of bovine leukemia virus taxresponsive genes in ovine B cells," Journal of Virology, vol. 80, no. 4, pp. 1922-1938, 2006.

[41] M. E. Stegenga, S. N. van der Crabben, M. C. Dessing et al., "Effect of acute hyperglycaemia and/or hyperinsulinaemia on proinflammatory gene expression, cytokine production and neutrophil function in humans," Diabetic Medicine, vol. 25, no. 2, pp. 157-164, 2008.

[42] A. Kahn, M. C. Meienhofer, and D. Cottreau, "Phosphofructokinase (PFK) isozymes in man. I. Studies of adult human tissues," Human Genetics, vol. 48, no. 1, pp. 93-108, 1979.

[43] E. B. Carson-Walter, D. N. Watkins, A. Nanda, B. Vogelstein, K. W. Kinzler, and B. St. Croix B., "Cell surface tumor endothelial markers are conserved in mice and humans," Cancer Research, vol. 61, no. 18, pp. 6649-6655, 2001.

[44] A. Figueroa, H. Kotani, Y. Toda et al., "Novel roles of Hakai in cell proliferation and oncogenesis," Molecular Biology of the Cell, vol. 20, no. 15, pp. 3533-3542, 2009.

[45] H. Hayashi, H. Wada, T. Yoshimura, N. Esaki, and K. Soda, "Recent topics in pyridoxal 5'-phosphate enzyme studies," Annual Review of Biochemistry, vol. 59, pp. 87-110, 1990.

[46] K. Sooy, T. Schermerhorn, M. Noda et al., "Calbindin-D(28k) controls $[\mathrm{Ca} 2+](\mathrm{i})$ and insulin release. Evidence obtained from calbindin-D(28k) knockout mice and $\beta$ cell lines," Journal of Biological Chemistry, vol. 274, no. 48, pp. 3434334349, 1999.

[47] E. Ostergaard, "Disorders caused by deficiency of succinateCoA ligase," Journal of Inherited Metabolic Disease, vol. 31, no. 2, pp. 226-229, 2008.

[48] S. Vora, "Isozymes of human phosphofructokinase: biochemical and genetic aspects," Isozymes, vol. 11, pp. 3-23, 1983.

[49] M. Nakata, K. Manaka, S. Yamamoto, M. Mori, and T. Yada, "Nesfatin-1 enhances glucose-induced insulin secretion by promoting $\mathrm{Ca}^{2+}$ influx through L-type channels in mouse islet $\beta$-cells," Endocrine Journal, vol. 58, no. 4, pp. 305-313, 2011.

[50] M. D. Meglasson and F. M. Matschinsky, "Pancreatic islet glucose metabolism and regulation of insulin secretion," Diabetes/Metabolism Reviews, vol. 2, no. 3-4, pp. 163-214, 1986.

[51] T. P. O'Hanlon, L. G. Rider, L. Gan et al., "Gene expression profiles from discordant monozygotic twins suggest that molecular pathways are shared among multiple systemic autoimmune diseases," Arthritis Research and Therapy, vol. 13, no. 2, article R69, 2011.

[52] E. Sagiv, M. Sheffer, D. Kazanov et al., "Gene expression following exposure to celecoxib in humans: pathways of inflammation and carcinogenesis are activated in tumors but not normal tissues," Digestion, vol. 84, no. 3, pp. 169-184, 2011.

[53] V. Skov, D. Glintborg, S. Knudsen et al., "Pioglitazone enhances mitochondrial biogenesis and ribosomal protein biosynthesis in skeletal muscle in polycystic ovary syndrome," PLoS ONE, vol. 3, no. 6, Article ID e2466, 2008.

[54] T. Haque, D. Faury, S. Albrecht et al., "Gene expression profiling from formalin-fixed paraffin-embedded tumors of pediatric glioblastoma," Clinical Cancer Research, vol. 13, no. 21, pp. 6284-6292, 2007.

[55] T. A.S. Jacobson, J. Lundahl, H. Mellstedt, and A. Moshfegh, "Gene expression analysis using long-term preserved formalin-fixed and paraffin-embedded tissue of non-small cell lung cancer," International Journal of Oncology, vol. 38, no. 4, pp. 1075-1081, 2011.

[56] M. S. Scicchitano, D. A. Dalmas, M. A. Bertiaux et al., "Preliminary comparison of quantity, quality, and microarray performance of RNA extracted from formalin-fixed, paraffinembedded, and unfixed frozen tissue samples," Journal of Histochemistry and Cytochemistry, vol. 54, no. 11, pp. 12291237, 2006.

[57] S. K. Penland, T. O. Keku, C. Torrice et al., "RNA expression analysis of formalin-fixed paraffin-embedded tumors," Laboratory Investigation, vol. 87, no. 4, pp. 383-391, 2007. 


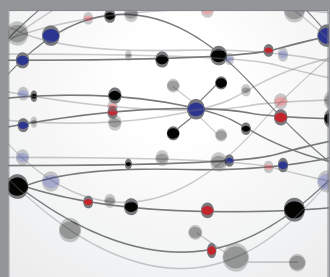

The Scientific World Journal
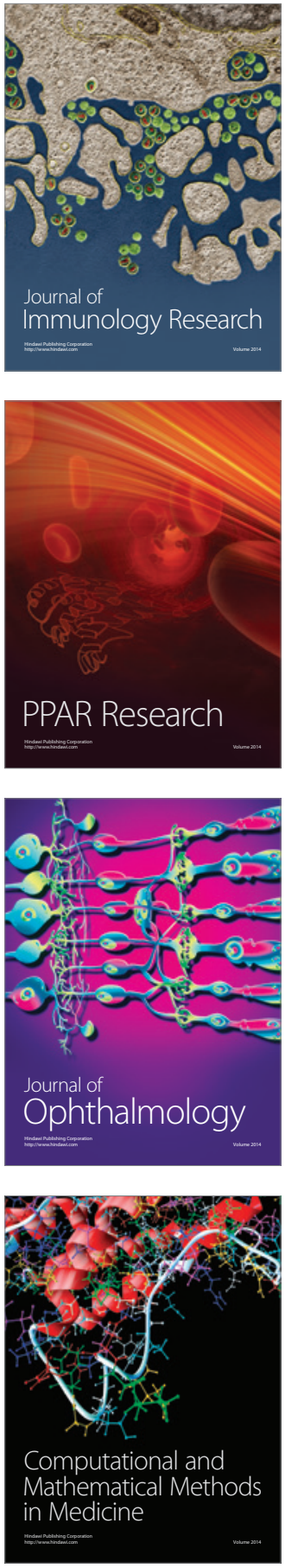

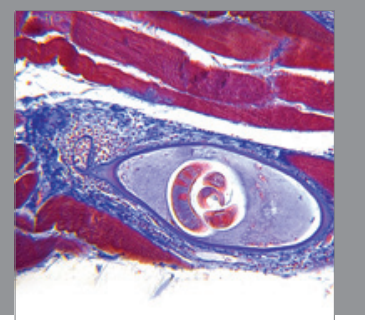

Gastroenterology

Research and Practice
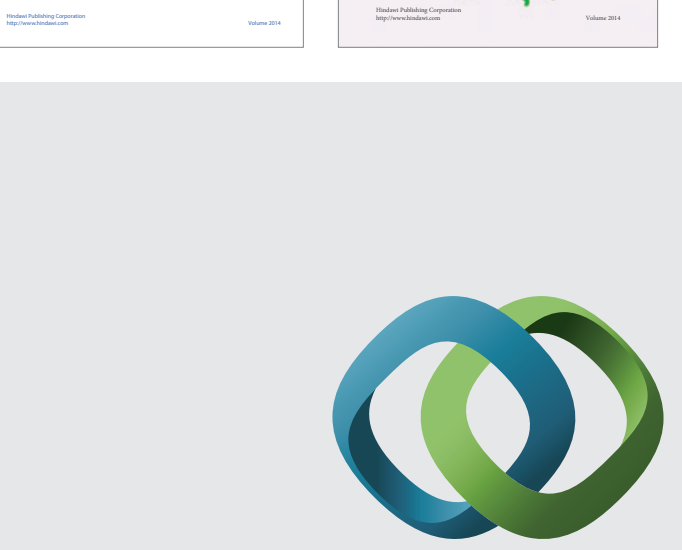

\section{Hindawi}

Submit your manuscripts at

http://www.hindawi.com
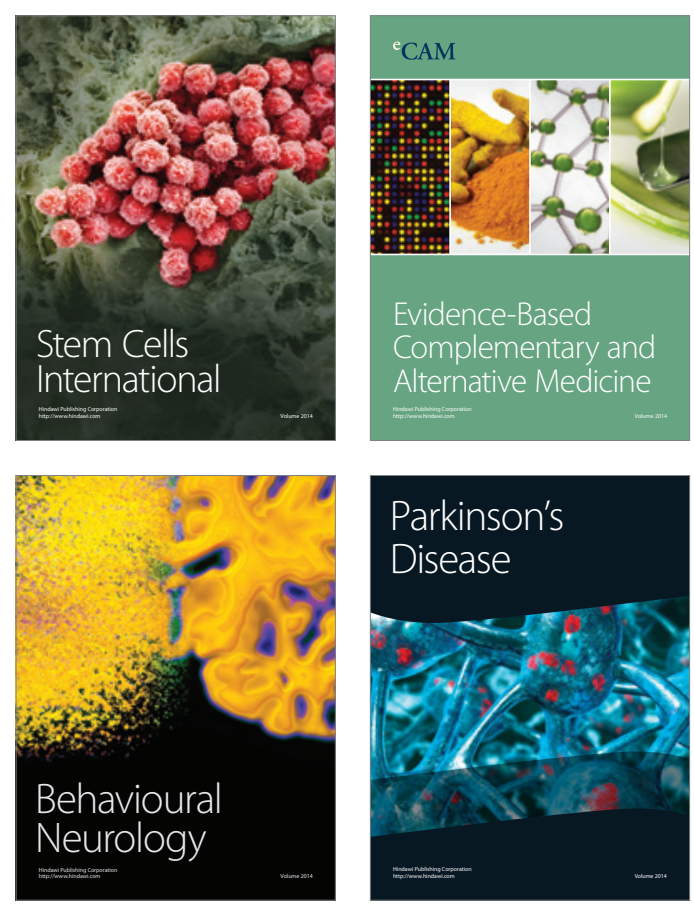

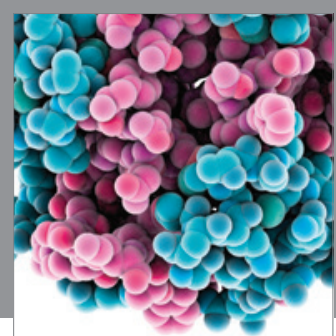

Journal of
Diabetes Research

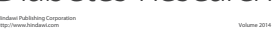

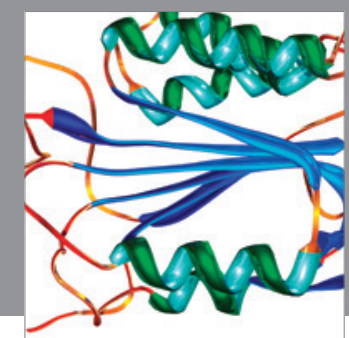

Disease Markers
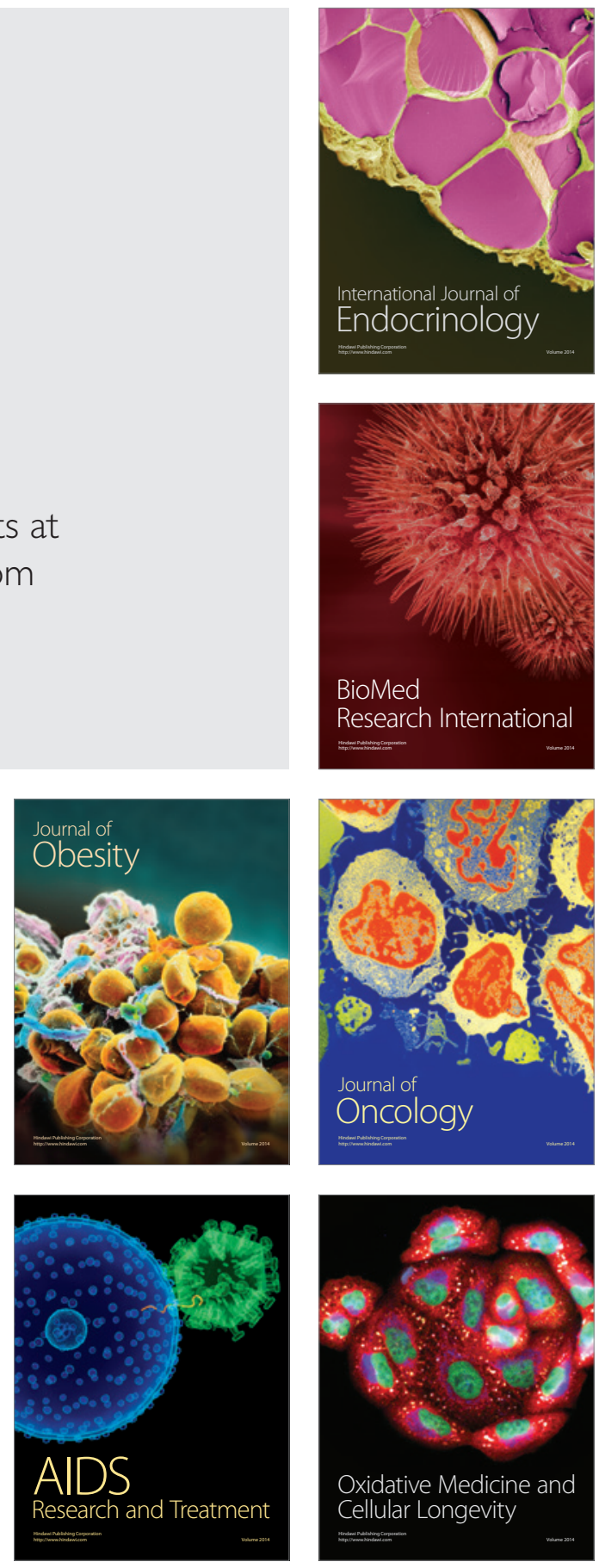